\title{
AREAL DOSIMETRY AT RESEARCH CENTRES
}

\author{
Roland Lüscher* \\ Paul Scherrer Institut, CH-5232 Villigen PSI, Switzerland \\ *Corresponding author: roland.luescher@psi.ch
}

\begin{abstract}
Radiation protection regulations apply to research centres and nuclear facilities alike. Radiological dose resulting from their activities is strictly limited by law; therefore, it has to be monitored. As a supplement to the personal dosimetry systems (mainly for the work force classified as occupationally exposed), areal dosimetry is an efficient surveillance tool. Serving as an example, the concept of areal dosimetry applied at the Paul Scherrer Institut is presented.
\end{abstract}

\section{INTRODUCTION}

Accelerator centres and nuclear facilities are submitted to the same regulations and legal guidelines on radiation protection. These include limitations on dose to the surrounding environment, as well as to the people living in the vicinity or to the work force on site. Swiss radiation protection regulation, as in most countries, is based on the recommendation from the International Commission on Radiation Protection ${ }^{(1)}$. The annual limit on dose defined in the Radiological Protection $\mathrm{Act}^{(2)}$ is $20 \mathrm{mSv}$ for people occupationally exposed and $1 \mathrm{mSv}$ for members of the public.

From these values, limitations to the ambient dose rates are extracted, based on parameters such as zone concepts and occupancy rates. These guidelines are regulated by the Swiss authorities (the Federal Office of Public Health and the Federal Nuclear Inspectorate (ENSI)).

The Paul Scherrer Institut (PSI) is the largest research centre for natural and engineering sciences in Switzerland. It operates several beam facilities, such as the world's most intense proton beam accelerator (1 MW) with a neutron spallation (SINQ) and muon source $(\mathrm{S} \mu \mathrm{S})$, a synchrotron light source (SLS) and a proton therapy centre. It also hosts nuclear facilities, such as a 'Hot Laboratory', two nuclear plants currently in decommissioning and a $0 \mathrm{~W}$ research nuclear plant (Proteus).

The above-mentioned limits and regulations impact naturally on all projects, old or new. It constrains the design of new facilities on issues such as shielding material or thickness; it has consequences on the concept of supervised or controlled areas in and around a given facility; ventilation systems, access controls, emission monitoring, etc., have all to be adapted according to these legal boundaries. Of course, within this legal frame, PSI has a reporting duty to the Swiss authorities. In theses regular reports, areal dosimetry plays an essential role. Beyond this latter point, the areal dosimetry has also proved to be a very useful tool for monitoring a clean beam operation: it may help identifying locations of unwanted beam losses and, thus, bringing increased beam reliability and availability.

\section{DEFINITION OF RADIOLOGICAL ZONES}

Zones in Swiss nuclear power plants are defined according to an ENSI guideline ${ }^{(3)}$. Zones are differentiated on the bases of dose rates (areal type $\mathrm{V}-\mathrm{Z}$ ) and/or on contamination risks (zone type $0-I V$ ). For details, see Table 1. These definitions impact on allowed occupancy rates (and hence, access control) as well as on vestimentary constraints (such as overalls and breathing apparatus).

The specificities of accelerator facilities reside in the major difference in radiation risk between beam on and beam off. However, after connecting the access control system to the beam status (with possible introduction of air purging time after beam operation), it becomes clear that similar zone concepts can be applied. Thus, PSI uses the same definitions in both, its nuclear and accelerator facilities.

\section{PASSIVE DOSIMETRY}

The facility and area ambient dose equivalent $H^{*}(10)$ dosemetry is surveyed by a net of approximately 270 measuring positions. The gamma-dose is recorded by $\mathrm{Al}_{2} \mathrm{O}_{3}$ and ${ }^{7}$ LiF-based thermoluminescence dosemeters (TLDs). The neutron dose is integrated by fission track dosemeters: ${ }^{235} \mathrm{U}$ converters in moderator spheres (diameter: $23 \mathrm{~cm}$ ) and ${ }^{232} \mathrm{Th}$ converters (with $0.1 \% \mathrm{U}$ content), respectively. The dosemeters are evaluated quarterly by the PSI dosimetry group and the recorded values reported to the authorities.

The choice of dosemeter is based on the expected dose and the expected energy spectrum. For gamma-dosimetry, $\mathrm{Al}_{2} \mathrm{O}_{3}$ is preferred in the non-classified areas, while the "standard' ${ }^{7} \mathrm{LiF}$ is used in the classified zones. The former has a higher sensitivity to lower energies, while the latter has a broader 


\section{R. LÜSCHER}

Table 1. Radiological zonetypes as defined in Swiss guidelines.

\begin{tabular}{lll}
\hline Area type & \multicolumn{1}{c}{ Dose rate $(\dot{\mathrm{D}})$} \\
\hline $\mathrm{V}$ & $\dot{\mathrm{D}}<0.01 \mathrm{mSv} \mathrm{h}^{-1}$ & \\
$\mathrm{~W}$ & $0.01<\dot{\mathrm{D}}<0.1 \mathrm{mSv} \mathrm{h}^{-1}$ \\
$\mathrm{X}$ & $0.1<\dot{\mathrm{D}}<1 \mathrm{mSv} \mathrm{h}^{-1}$ & \\
$\mathrm{Y}$ & $1<\mathrm{D}<10 \mathrm{mSv} \mathrm{h}^{-1}$ & \\
$\mathrm{Z}$ & $10<\dot{\mathrm{D}}$ & \\
Zone type & Level of surface & Level of air \\
& contamination $\left(\mathrm{K}_{s}\right)$ & contamination $\left(\mathrm{K}_{a}\right)$ \\
0 & $\mathrm{~K}_{s}<1 \mathrm{CS}^{\mathrm{a}}$ & $\mathrm{K}_{a}<0.05 \mathrm{CA}$ \\
I & $\mathrm{K}_{s}<1 \mathrm{CS}$ & $\mathrm{K}_{a}<0.1 \mathrm{CA}^{2}$ \\
II & $1<\mathrm{K}_{s}<10 \mathrm{CS}$ & $\mathrm{K}_{a}<0.1 \mathrm{CA}$ \\
III & $10<\mathrm{K}_{s}<100 \mathrm{CS}$ & $0.1<\mathrm{K}_{a}<10 \mathrm{CA}$ \\
IV & $100 \mathrm{CS}^{2}<\mathrm{K}_{s}$ & $10 \mathrm{CA}<\mathrm{K}_{a}$ \\
\hline
\end{tabular}

${ }^{\mathrm{a}} \mathrm{CS}, \mathrm{CA}$ : Guideline values, isotope dependent, for surface, resp. air contamination as defined in Appendix 3 of SR 814.501 Radiological Protection Ordinance ${ }^{(2)}$.

Table 2. Characteristics of the dosemeter used for areal dosimetry at PSI.

\begin{tabular}{lll}
\hline Type & Measuring range & \multicolumn{1}{c}{ Energy range } \\
\hline${ }^{\mathrm{Al}_{2} \mathrm{O}_{3}}$ & $0.1-100 \mathrm{mSv}$ & $0.03-6 \mathrm{MeV}$ \\
${ }^{7} \mathrm{LiF}$ & $0.1 \mathrm{mSv}-5 \mathrm{~Sv}$ & $0.03-6 \mathrm{MeV}$ \\
${ }^{235} \mathrm{U}^{232}$ conv. $^{\mathrm{a}}$ & $0.02-20 \mathrm{mSv}$ & Thermal to $20 \mathrm{MeV}$ \\
${ }^{23}$ Th conv. $^{\mathrm{b}}$ & $0.3-300 \mathrm{mSv}$ & Thermal to high energy \\
\hline
\end{tabular}

${ }^{\mathrm{a}}$ With moderator sphere.

${ }^{\mathrm{b}}$ With $0.1 \% \mathrm{U}$ content.

measurement range. Three TLDs are used at every measuring point for the purpose of cross-checks. All dosemeters are calibrated in $H^{*}(10)$, the ambient dose equivalent, at the PSI calibration facility. An uncertainty of $20 \%$ is evaluated for a TLD at the reference energy of the ${ }^{137} \mathrm{Cs}$-line. The moderator sphere is used with ${ }^{235} \mathrm{U}$ converters in order to extend the energy range up to $20 \mathrm{MeV}$. Two devices are set at every measuring point. An uncertainty of $30 \%$ is evaluated, based on a calibration with an $\mathrm{Am} / \mathrm{Be}$ source. The main characteristics of the dosemeters used at PSI for areal dosimetry are summarised in Table 2.

Measuring points are defined by the operational radiation protection group. Locations are classified into two categories: areal and facility dosimetric points (inside classified zones: laboratories, active workshops, etc.). The former consists of areas outside classified areas, such as offices, inactive workshops, roads, passages, etc. Special care is given to monitor the dose at the fence of the PSI area, as a mean to evaluate the direct radiation to the environment. As non-classified workers or visitors can be expected at these points, an upper guideline value of $1 \mathrm{mSv} \mathrm{y}^{-1}$ shall not be exceeded. However, one differentiates between inside and respectively outside buildings, for instance near the fences, where occupancy rates can reasonably be assumed to be low (Figure 1). There, a guideline value of $5 \mathrm{mSv} \mathrm{y}^{-1}$ is tolerated ${ }^{(3)}$.

Classified zones are subdivided into workplaces with permanent stay (where high occupancy rates can be expected) or temporary stay (with low occupancy rate) and off-limit areas. The latter are not accessible during operation without the explicit permission and under constant supervision of the operational radiation protection. Occupancy rate is therefore the main parameter guiding the placement of measurement points (Figure 2). A guideline threshold of $80 \mathrm{mSv} \mathrm{y}^{-1}$ is valid for the first subcategory, based on the definition of a type ' $V$ ' $z$ zone ${ }^{(3)}$. This value is extended to $200 \mathrm{mSv} \mathrm{y}^{-1}$ for low occupancy rate locations, following Appendix 2 of SR814.554 ordinance $^{(4)}$. As for off-limit areas, no limits are defined. Obviously, the guideline thresholds applying to the surroundings have to be observed, whereas effects such as sky-shine have to be taken into account.

The accumulated doses are evaluated quarterly using this net of passive dosimetry. This allows not only to fulfil the regular duty of reporting to the authorities, it also enables the study of long-term effects, such as an increase in beam intensity, the step-by-step commissioning of a newly built facility or the area surrounding an upgraded beam line instrument. PSI being a research centre, often changing conditions call for a regular review of the network of measuring points, redefining and relocating them.

\section{ACTIVE DOSIMETRY}

While long-term studies are best covered using passive dosimetry, flexibility to short-term changes (a specific experiment on a beam line, for instance, or temporary problems with beam components or increased beam losses) are better covered with active, online devices.

For this purpose, a network of measuring points is defined. Detectors are chosen according to the expected radiation field in first instance. Other important criteria are robustness and ease of operation. The measurements are transferred via an RS485 bus to a central unit, where the data are recorded. The data are collected with the MEVIS (Centralised MEasurement VISualisation and data archiving $)^{(5)}$ software, which also enables the visualisation of recorded values at any given time. This gives a tool for instant evaluation of any changes, as dose rate and beam current can be analysed 


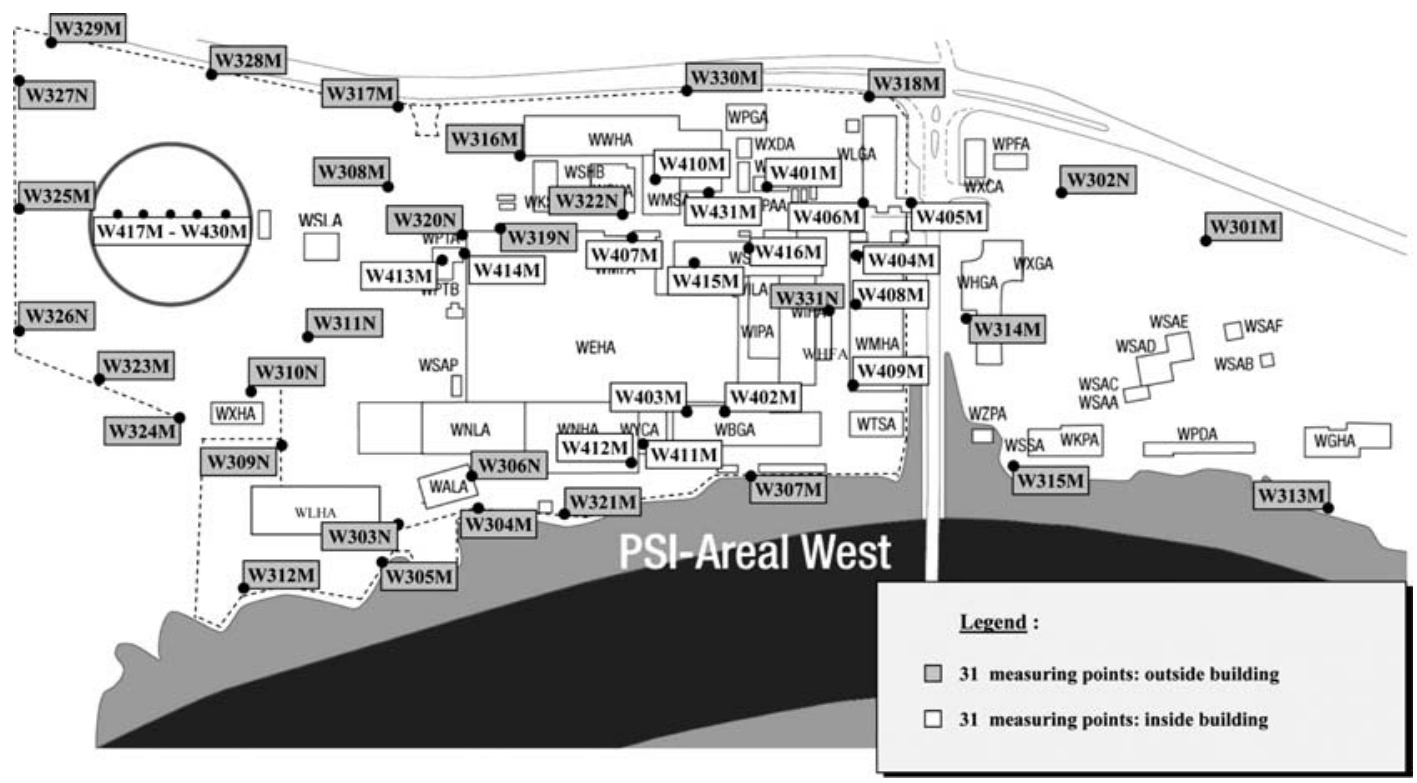

Figure 1. Measuring points for areal dosimetry outside classified zones, for PSI-West.

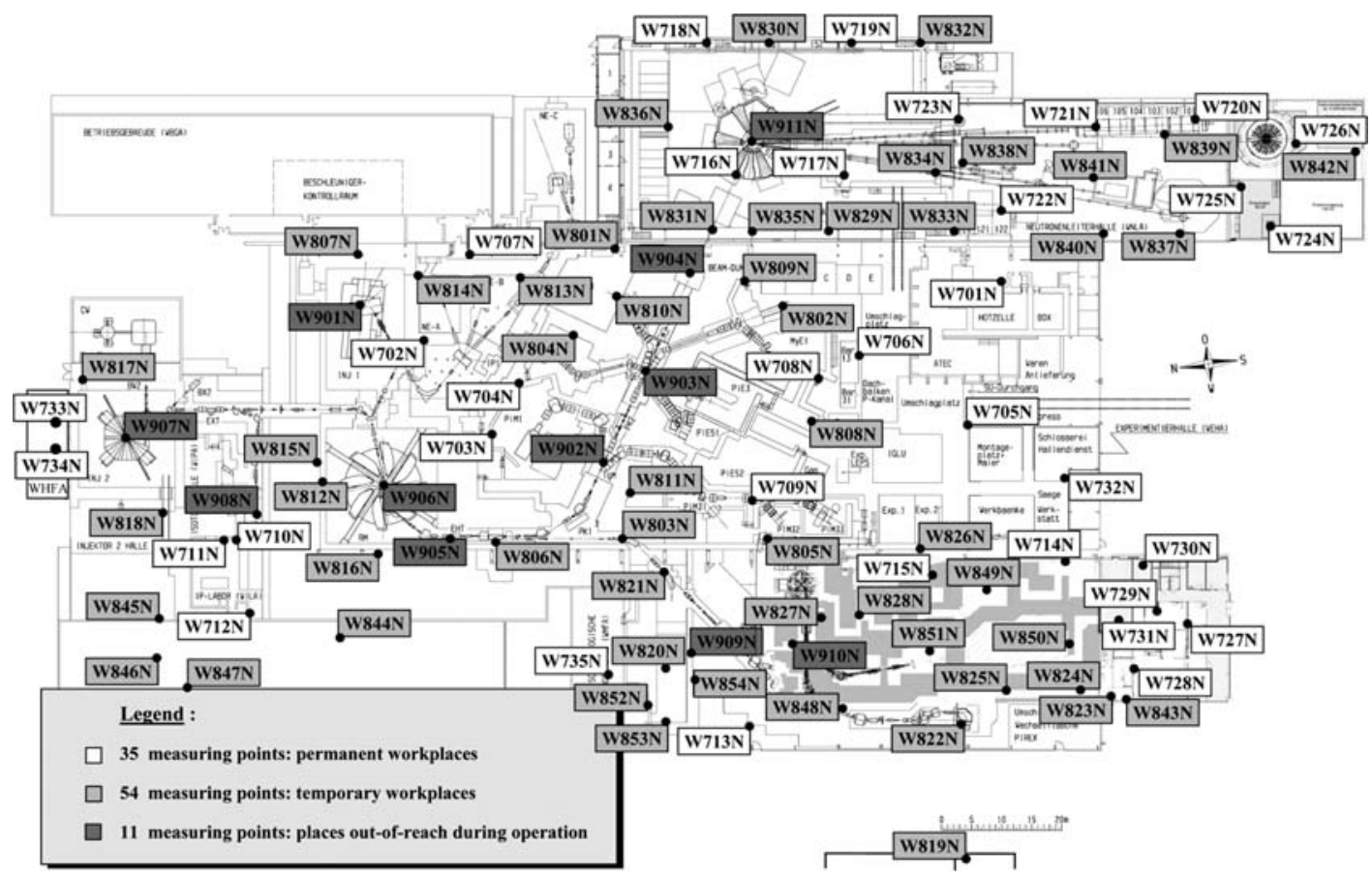

Figure 2. Measuring points for areal dosimetry inside classified zones, at the p-accelerator facility, PSI-West.

synchronously (Figure 3). These measurements are naturally backed up, as evidence for reporting purposes.
For neutron radiation fields, the LB6411 device from Berthold Technologies ${ }^{(6)}$ is used as a standard. Depending on the necessary measuring range, 

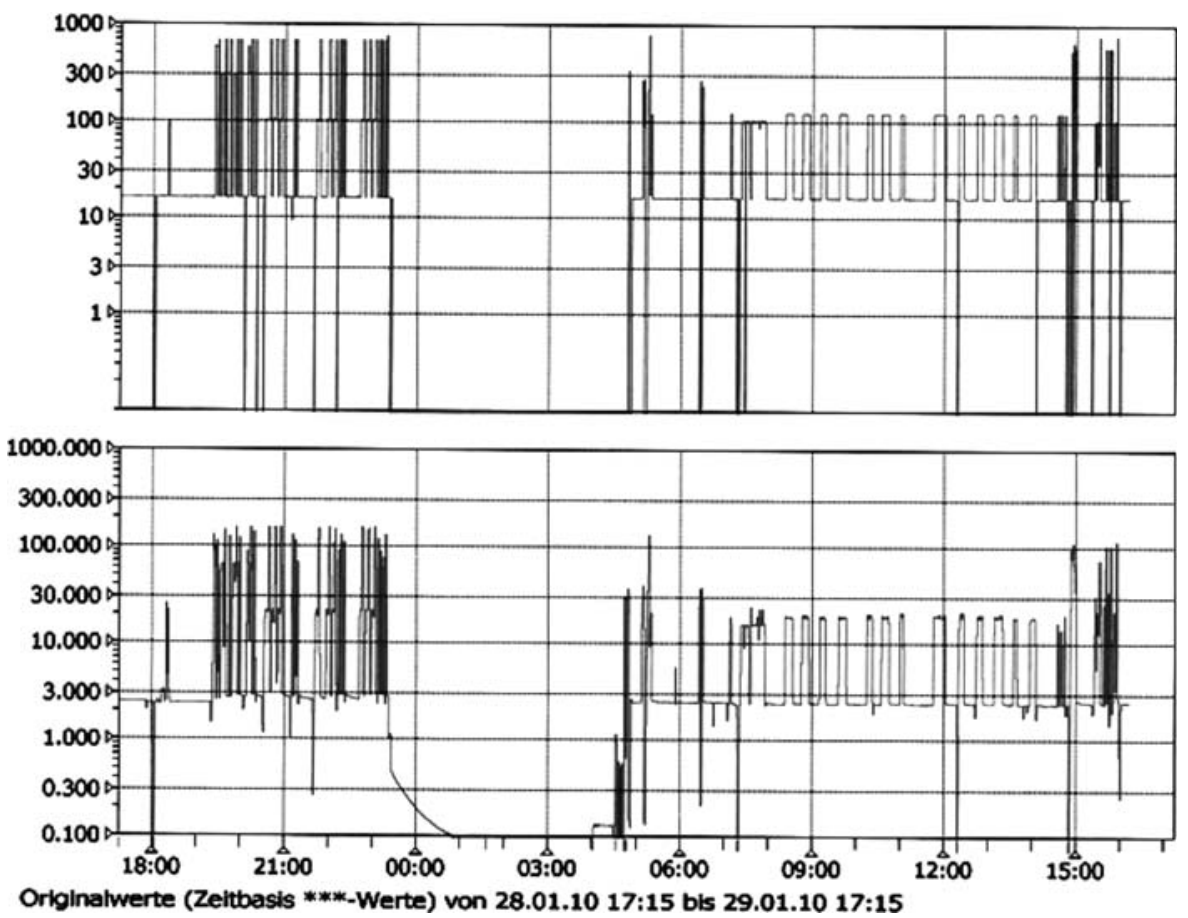

Figure 3. Active areal dosimetry: example of synchronous analysis between beam current (top, in $\mathrm{nA}$ ) and dose rate (bottom, in $\mathrm{mSv} \mathrm{h}^{-1}$ ) at the p-therapy accelerator facility. Note the exponential decrease of the latter at around 23:00 as the beam is stopped: this is due to the decay of air activation products.

Table 3. Characteristics of the active devices used for areal dosimetry at PSI.

\begin{tabular}{|c|c|c|}
\hline Type & Measuring range & Energy range \\
\hline LB6360-H10 ${ }^{(6) a}$ & $0.1-20 \mathrm{mSv} \mathrm{h}^{-1}$ & $35-1300 \mathrm{keV}$ \\
\hline LB $6500-4^{(6) a}$ & $1 \mathrm{E}-4$ to $1 \mathrm{mSv} \mathrm{h}^{-1}$ & $55-2000 \mathrm{keV}$ \\
\hline Centronic $\mathrm{IG} 5^{(8) \mathrm{b}}$ & $0.01-100 \mathrm{mSv} \mathrm{h}^{-1}$ & 60 to $10 \mathrm{E} 3 \mathrm{keV}$ \\
\hline PTW 31-Ch. ${ }^{(7) b}$ & $<10 \mathrm{~Sv} \mathrm{~h}^{-1}$ & $80-1300 \mathrm{keV}$ \\
\hline LB6411 $1^{(6) c}$ & $0.1-100 \mathrm{mSv}^{-1} \mathrm{~h}$ & Thermal to $20 \mathrm{MeV}$ \\
\hline
\end{tabular}

${ }^{\mathrm{a}}$ Geiger-Müller detectors.

${ }^{\mathrm{b}}$ Ionisation chambers.

${ }^{\mathrm{c}}$ Neutron monitor.

gamma-monitoring is performed using either Geiger-Müller-counters or ionisation chambers. The devices used in the active areal dosimetry at PSI are summarised in Table 3.

This system is therefore combining the robustness of an industry standard network with the appropriate detecting sensitivity. The network based on RS485 allows also flexibility: a mobile detector system can be hooked up to the network at any given connection box, which are set up throughout our facilities (Figure 4). This gives the opportunity to easily concentrate a tighter surveillance around

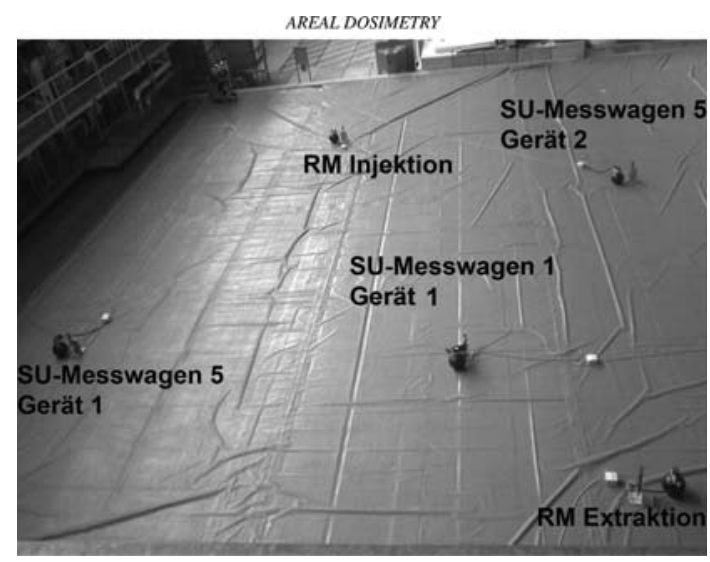

Figure 4. Active areal dosimetry: example of a deployment of mobile devices. The position of each detector is optimised as to record the dose rate at the most strategic spots. The view is showing the roof of the Ring cyclotron, part of the p-accelerator facility.

new or upgraded beam lines or facilities during their commissioning, or experiments with higher radiological issues. 


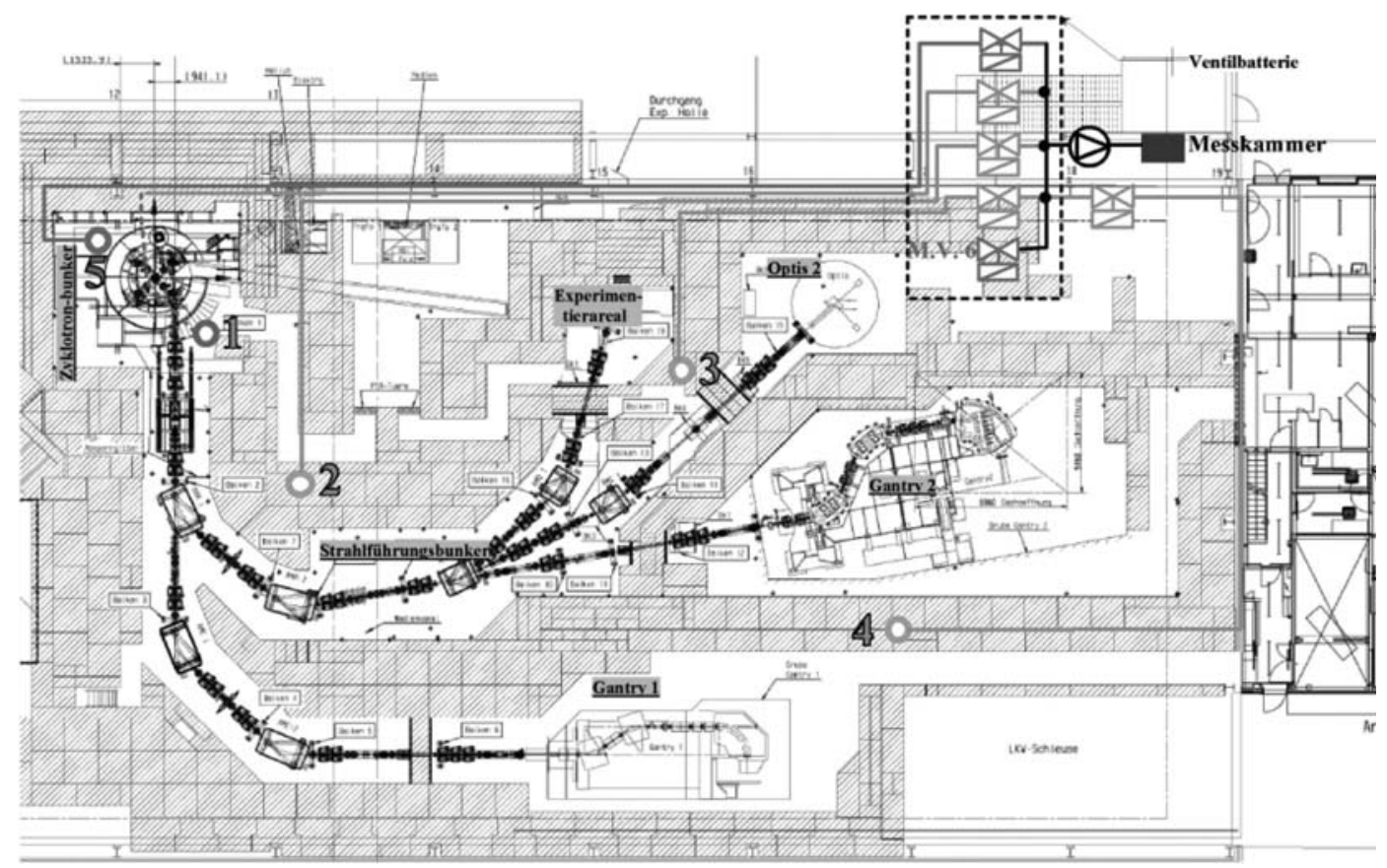

Figure 5. Air monitoring: overview of the air probing system at the p-therapy facility.

The operation of a given facility is not directly coupled to its active areal dosimetry network. However, the following cases do generate a warning or alarm: the number of connected devices is below the agreed threshold (fixed in the operation instructions); the activity at one location is above warning, respectively alarm threshold. If such an event occurs, the operation team is instructed to call the radiation protection and might have to stop the operation. The synchrotron facility SLS is, for instance, not operated if $<8$ device units are connected. For ease of operation, the experimental areas are not classified as zones; therefore, the limit is $1 \mathrm{mSv} \mathrm{y}^{-1}$. This is monitored by the active areal dosimetry network, whereas the measured dose rate is integrated over a week and shall not exceed $20 \mu \mathrm{Sv}$ week ${ }^{-1}$. Warning and alarm levels are adapted to zone types and radiation risks.

\section{AIR ACTIVATION MONITORING}

As can be seen from the definitions given earlier, possible contamination of the air does influence the classification of radiological zones. As a consequence, monitoring of the air activity is paramount. A network consisting of air probe lines has been set up, driving samples of airs to monitoring devices (Figure 5). In this way, the air is assessed in terms of ${ }^{3} \mathrm{H}$ and $\beta^{+}$activities. The former is obtained with a
Tritium monitor $\mathrm{LB} 671^{(6)}$. For the latter, the air is directed into a gas chamber (of about 201 ), in which a standard $\mathrm{NaI}$ crystal detects the $511 \mathrm{keV}$ annihilation line.

\section{MANUAL DOSE RATE MAPPING}

No network of passive or active devices can cover without any gap the surveillance of a given facility. For this purpose, nothing replaces mapping campaigns, operated by the radiation protection group using portable devices. A mapping is obtained by measuring systematically the dose rate around a shielded facility, while it is running in the least favourable conditions, i.e. the highest the beam intensity, the most demanding the beam operation. For instance, the Gantry from the proton-therapy centre is driven into a horizontal position for the purpose of the measurement campaign, as this direction causes the most stringent shielding constraints.

The measuring points in any campaign are defined in high numbers (tens and hundreds) and high density. This has the purpose of identifying possible shielding weaknesses, which could be arbitrarily small. Often, the results of the campaigns feed directly into defining the measuring points of both the active and the passive areal dosimetry network. 


\section{R. LÜSCHER}

As 'portable' neutron device, the standard LB6411 ${ }^{(6)}$ is again used. For gammas, either a standard Thermo/Bicron micro Sievert LE or a TOL/ $F^{(6)}$ is used, depending on the expected energy range.

\section{CONCLUSION}

For the purpose of its reporting duties to the Swiss authorities, PSI has set up a network of passive and active areal dosimetry. With these tools, the operational radiation protection can survey a safe operation of the large facilities. Particular care is given to review and update these networks regularly, responding to ever-changing conditions, typical of a research centre. Beyond these efforts, regular mapping campaigns are performed, particularly during commissioning of a new facility or beam line. These methods complement each other, each fulfilling an important part in the radiation protection jigsaw.

\section{REFERENCES}

1. ICRP 103. The 2007 Recommendations of the International Commission on Radiological Protection. ICRP Publication, Ann. ICRP 37, $2-4$ (2007). Swiss regulations are however still based on the earlier ICRP 60. Ann. ICRP 21, 1-3 (1991). Available on: http:// www.icrp.org/publication.asp?id=ICRP $\% 20$ Publication $\%$ 20103.

2. SR 814.50. Radiological Protection Act; SR 814.501 Radiological Protection Ordinance.

3. Guideline for the supervised areas in nuclear facilities and the Paul Scherrer Institut HSK-R-07 Federal Nuclear Safety Inspectorate, (1995).

4. SR 814.554. Ordinance on the Handling of unsealed radiological Sources.

5. UMAD. Umweltmesstechnik- und Datenverarbeitungsgesellschaft GmbH Available on: http://www.umad.de.

6. Berthold Technologies $\mathrm{GmbH} \&$ Co. Available on: http://www. bertholdtech.com.

7. PTW Freiburg GmbH Available on: http://www.ptw.de.

8. Centronic Ltd Available on: http://www.centronic.co.uk. 